\title{
Kavun türünde yaprak alanının matematiksel modeller ile tahminlenmesi
}

\author{
Estimation of leaf area in melon species with mathematical models
}

\author{
Kazım MAVi' ${ }^{(D)}$, Sefer BOZKURT ${ }^{2}$, Fulya UZUNOĞLU1 \\ ${ }^{1}$ Hatay Mustafa Kemal University, Faculty of Agriculture, Department of Horticulture, Antakya-Hatay, Turkey. \\ ${ }^{2}$ Hatay Mustafa Kemal University, Faculty of Agriculture, Department of Biosystems Engineering, Antakya-Hatay, Turkey.
}

MAKALE BILGISI / ARTICLE INFO

Makale tarihçesi / Article history:

DOI: $10.37908 /$ mkutbd. 745377

Geliş tarihi /Received:30.05.2020

Kabul tarihi/Accepted:13.07.2020

\section{Keywords:}

Leaf area, Growth model, Leaf area index, Water stress.

\footnotetext{
Corresponding author: Fulya UZUNOĞLU

$\bowtie$ : fulyaacikgoz@gmail.com
}

\section{Ö ZET / A B STR A C T}

Atıf / Citation: Mavi K, Bozkurt S, Uzunoğlu F (2020) Kavun türünde yaprak alanının matematiksel modeller ile tahminlenmesi. MKU. Tar. Bil. Derg. 25(1) : 370-382. DOI: 10.37908/mkutbd.745377 


\section{Giriş}

Latince'deki adı Cucumis melo olarak bilinen kavunun anavatanı Asya'dır. Kavun vitamin ve mineral açısından zengin, sevilerek yenilen tatlı ve sulu meyvelere sahip bir bitkidir. Ülkemiz kavunun önemli gen merkezlerinden birisidir. Dünya toplam kavun üretimi içinde Türkiye, Çin'den sonra ikinci sırada yer almaktadır. Türkiye'de 2019 yılında 1777059 ton olan toplam kavun üretiminin, 205,430 tonu örtü altında üretilmiştir (Anonim 2019). Örtüaltı yetiştiriciliğinde daha çok Cucumis melo L. var. cantalupensis grubuna giren, erkenci ve küçük meyveli kantolop tipli kavun çeşitleri tercih edilmektedir (Yarşı ve Sarı, 2006).

Bitki büyümesi ve gelişmesi için mutlak gerekli bir element olan kalsiyum; hücre büyüme ve gelişme sürecinde, membran geçirgenliğinin ayarlanmasında, dokuların yenilenmesinde ve bitkilerin kalite ile ilgili özelliklerini kazanmasında oldukça önemli rollere sahip bir makro elementtir (Marschner,1995). Yapraktan ve topraktan uygulanan farklı çeşit ve dozlarda kalsiyum bileşiklerinin, karpuz bitkisinde verim, kalite ve beslenme durumu üzerine etkili olduğu bildirilmiştir (Tuna ve Özer, 2005).

Kuraklık, tarımsal üretimler üzerinde büyük bir etkiye sahip olup, üretimi sınırlandıran en önemli abiyotik streslerden biridir. Bitkiler de kuraklık stresi; stresin yoğunluğu ve süresine bağlı olarak bitki çeşidine ve gelişim aşamasına göre farklı şekillerde tepkiler gösterirler. Bitkilerin gösterdikleri bu tepkiler, stres faktörüne dayanımın ortaya çıkmasında büyük bir öneme sahiptir (Jaleel ve ark., 2007; Reddy ve ark., 2004).

Kuraklık stresi bitkilerde büyüme ve verim, bitkinin vegetatif ve generatif organları arasında su rekabeti, hücre içi yapılar, fotosentez ve azot metabolizması üzerine olumsuz etkilerde bulunarak bitki metabolizmasını bozmaktadır (Kocaçalışkan, 2003). Ayrıca kuraklık sırasında büyüme için bir itici güç olan turgor basıncının azalması ve transpirasyonun olumsuz etkilenmesi nedeniyle mineral madde alımının gerilemesine de neden olabilmektedir (Capell ve ark., 2004).

Yapraklar, ışık enerjisinin tutulduğu ve bitki büyümesi için gerekli olan metabolitlerin üretiminde kullanıldığı en önemli organlardır (Kanemasu ve ark. 1985). Yaprak alanı, bitki büyümesini ve verimliliği teşvik etmektedir (Kandiannan ve ark. 2002).

Yapraklar fotosentez ve evapotranspirasyonla (ET) ilişkili olup, yaprak büyümesinin ölçülmesi bitki gelişiminin yanı sıra çoğu agronomik ve fizyolojik çalışmaların değerlendirilmesinde kullanılan bir uygulamadır (Guo ve
Sun 2001). Yaprak alanı tahmini ile ilgili yöntemlerin çoğu budama veya söküm işlemlerinin yanı sıra, zahmetli veya zaman alıııdır. Yaprakların budandığı örnekleme yöntemleri, özellikle küçük parseller veya az sayıda bitki ile çalışıldığından, genellikle tercih edilmemektedir. Bunun yanı sıra, bazı diğer yöntemler ise pahalı ekipman kullanımı ve bu ekipmanların kullanımı için yüksek düzeyde teknik yeterlilik, işletme ve bakım intiyaçları gerektirmektedir. Araştırmacıların bu koşulları sağlaması çoğu zaman mümkün olmamaktadır. Bu nedenle yaprak alanı tahmininde basit, ucuz ve yaprağa zarar vermeyen bir yöntemin geliştirilmesi önem kazanmaktadır.

Yaprak alanı, özellikle bitkideki yaprak sayısı ve yaprak büyüklüğüne bağlıdır. Bitkide yaprak sayısı ve büyüklüğü su stresi ve besin eksikliğinden olumsuz etkilenmektedir (Longnecker 1994). Bitkide su ve besin maddesi alınımının azalması fotosentezin yavaşlamasına neden olduğu için (Koç ve Barutçular, 2000) bitkilerin karbonhidrat metabolizması, kuru madde oluşumu, verim ve kalitesini de etkilemektedir (Centritto ve ark. 2000).

Yapraklara zarar vermeden yaprak alanı ölçümleri, araştırmacılara sürekli aynı bitki ve yaprakta çalışma fırsatı sağlaması ve dolayısıyla denemelerde ortaya çıkabilen yüksek varyasyon katsayılarını azaltma potansiyeli nedeniyle, yapraklara zarar veren alan ölçümlerine kıyasla çok daha fazla tercih edilmektedir. Ayrıca, basit doğrusal ölçümlerle yaprak alanlarının belirlenebilmesi çok pahalı ve karmaşık yaprak alan ölçüm cihazlarına gereksinimi ortadan kaldırmaktadır. Bu nedenlerle bireysel veya toplam yaprak alanlarının doğrusal yaprak ölçümleriyle elde edilen verilerden yararlanılarak oluşturulan matematiksel formüller ve modeller yardımıyla belirlenmesi bitki çalışmalarında oldukça yararlı olmaktadır (Çamaş ve ark. 2005)

Yaprak alanlarının doğrudan bitkiye zarar vermeden belirlenmesine yönelik farklı bitkiler için yapılmış çalışmalar (Manivel ve Weaver 1974; Sepaskhah 1977; Strik ve Proctor 1985; Robbins and Pharr 1987; Guo and Sun, 2001; Bozkurt ve Sayılıkan Mansuroğlu 2019) bulunmaktadır. Ancak, literatürde kavun yetiştiriciliğinde farklı su stresi ve kalsiyum dozlarının yaprak boyutlarına etkisini konu alan yapıımış herhangi bir çalışmaya rastlanılmamıştır.

$\mathrm{Bu}$ çalışma ile bilgisayara yükleyebildiğimiz basit bir yazılım sayesinde kavunda yaprak alan ölçümlerinin daha kısa sürede ve daha az hata ile sonuçlandırılması amaçlanmıştır. Bu nedenle çalışmanın amacı farklı $\mathrm{Ca}$ gübrelemesi ve su stresi koşullarında yetiştirilen kavun bitkilerinden elde edilen gerçek yaprak alanı verileri üzerinden kavun türünde yaprak alanının tahminlenmesinde kullanılabilecek bir matematiksel 
model geliştirmektir.

\section{MATERYAL ve YÖNTEM}

\section{Materyal}

Araştırmada bölgemizde yaygın olarak yetiştirilen ve beğenilen Citrex kavun (Cucumis melo L. var. cantalupensis ) çeşidi kullanılımışır.

\section{Yöntem}

Araştırmanın yaprak örneklemeleri araştırmacıların hâlihazırda yürüttükleri bağımsız bir araştırmadan alınmıştır. Uygulanan yöntemler aşağıda kaba hatları ile verilmiştir. Kavun bitkileri $(100 \times 50 \mathrm{~cm})$ x $50 \mathrm{~cm}$ sıra arası ve sıra üzeri mesafelerde çift sıralı dikilmiştir. Parseller $12.0 \mathrm{~m} \times 1.5 \mathrm{~m}$ boyutlarında $18 \mathrm{~m}^{2}$ alana sahiptir. Her konudan 30 yaprak olmak üzere toplam 1350 yaprakta çalışılmış olup, her konudan 10 yaprakla da modellerin geçerliliği test edilmiştir. Toplamda 1800 adet yaprakla çalışılmıştır. Farklı gelişmişliklere sahip yaprakların en (W), boy (L) ve alanları (LA) aşağıdaki yöntemlere göre belirlenmiştir. Ortalama yaprak alanları uygulamalara göre karşılaştırılarak yaprak alan büyüklüğüne etkileri belirlenmiştir. Ayrıca, elde edilen veriler yardımıyla yaprak alanı ile en ve boy parametreleri arasındaki ilişki farklı matematiksel formüllerle (Çizelge 1) açıklanmaya çalışılmış ve en uygun kavun yaprak alan belirleme modeli belirlenmiştir. En uygun alan belirleme modelinin belirlenebilmesi için doğrudan ölçümlerle elde edilen alan eğrileri 6 farklı matematiksel eşitlik kullanılarak modellenmiştir (Çizelge 1).

Çizelge 1. Araştırmada kullanılan matematiksel modeller Table 1. Mathematical models used in research

\begin{tabular}{|l|l|l|l|}
\hline No & Model & No & Model \\
\hline 1 & $\mathrm{LA}=\mathrm{a}+\mathrm{bL}$ & 4 & $\mathrm{LA}=\mathrm{a}+\mathrm{bL}^{2}$ \\
\hline 2 & $\mathrm{LA}=\mathrm{a}+\mathrm{bW}$ & 5 & $\mathrm{LA}=\mathrm{a}+\mathrm{bW}^{2}$ \\
\hline 3 & $\mathrm{LA}=\mathrm{a}+\mathrm{b}^{*}(\mathrm{~L}+\mathrm{W})$ & 6 & $\mathrm{LA}=\mathrm{a}+\mathrm{b}^{*}\left(\mathrm{~L}^{2}+\mathrm{W}^{2}\right)$ \\
\hline
\end{tabular}

$\mathrm{W}$ :Yaprak eni; L:Yaprak boyu; LA: Yaprak alanı; a ve b model katsayıları (boyutsuz)

\section{Yapılacak ölçümler ve izlenecek parametreler Yaprak geometrisi}

Yaprak şeklinin tanımlanmasında yaprak en ve boy ölçümlerinden (Şekil 1) faydalanılmıştır (Stewart ve
Dwyer 1993). Yaprağın en uzak iki noktası arası boy ve en geniş olduğu kısmı ise en olarak dikkate alınmış ve kumpas yardımıyla ölçülmüştür (Gülümser ve ark. 1998).



Şekil 1. Kavun yaprak en (W) ve boy (L) ölçümlerinin yapılış pozisyonu

Figure 1. The position of melon leaf width (W) and length (L) measurements

Yaprak alanı (LA): Bu ölçümler elektronik planimetre ile yapılmıştır. Bu kapsamda bitkilerden budanan yapraklar eskiz kâğıtlarına çizilmiş ve bu çizimlerden en boy ve alan ölçümleri yapılmıştır.

\section{Deneme deseni ve istatistik analiz}

Farklı boyutlara sahip yaprakların en (W), boy (L) ve alanları (LA) önceden belirtilen yöntemlerle belirlenip, ortalamaları karşılaştırılarak su stresinin yaprak alan 
geometrisine etkisi ortaya çıkarılmıştır. Ayrıca, elde edilen veriler yardımıyla yaprak alanı ile en ve boy parametreleri arasındaki doğrusal veya doğrusal olmayan ilişkiler farklı matematiksel formüllerle açıklanmaya çalışılmış ve en uygun model belirlenmiştir (Gomez ve Gomez 1984).

Matematiksel modelleme çalışmalarında UnScrambler (Versiyon 9.7) paket yazılımıkullanılmıştır. En iyi modelin belirlenmesinde RMSEP ve $\mathrm{R}^{2}$ değerleri kullanılmış olup, RMSEP değeri aşağıdaki eşitlikle hesaplanmıştır (Esbensen 2009):

$$
R M S E P=\sqrt{\frac{\sum_{i=1}^{N}\left(y_{i}-y_{i, r e f}\right)^{2}}{n}}
$$

Burada; yi: ölçülen alan, yi, ref: tahmin edilen alan ve $\mathrm{n}$ gözlemlenen deneysel veri sayısıdır.

Sonuçta, uygun görülen modelin MS-Ofis Excell programında programı oluşturulmuş ve sadece yaprakların en ve boy değerlerinin girilmesiyle, bireysel yaprak alanı (LA), toplam bitki yaprak alanı (TLA) ve bitki yaprak alan indeksi (LAI) değerlerinin direk belirlenmesi sağlanmıştır.

\section{BULGULAR ve TARTIŞMA}

Farklı sulama düzeylerinin ortalama yaprak alanı üzerindeki etkisi Çizelge 2 ve Şekil 2'de gösterilmiştir. Kısıtlı sulamaları temsil eden $I_{20}, I_{40}$ ve $I_{60}$ sulama düzeyinde yetiştirilen bitkilerden elde edilen ortalama yaprak alanı değerlerinin diğer sulama düzeylerine kıyasla daha düşük olduğu tespit edilmiştir (Çizelge 2, Şekil 2. En yüksek ortalama yaprak alanı $I_{80}$ sulama konusunda $26.2 \mathrm{~cm}^{2}$ olarak elde edilmiştir. Şekil 3' de de görüldüğü üzere ortalama yaprak alan değerleri uygulanan sulama suyu miktarları arttıkça belirli bir düzeye kadar artış göstermiş, yüksek su uygulamalarında ise kısmen düşüş göstermiştir. Buradan su uygulamalarının kısıtlı olduğu koşullarda ve aşırı su uygulamalarında bitki yaprak gelişiminin olumsuz etkilendiği görülmektedir.

Çalışmada farklı sulama düzeylerinde yetiştirilen bitkilerin yaprak eni, yaprak boyu ve yaprak alanı arasındaki ilişkiler incelenmiştir. Farklı sulama düzeyleri ve Ca uygulamaları için yaprak eni ve yaprak alanı ilişkileri Şekil 3'de, yaprak boyu ve yaprak alanı ilişkileri Şekil 4'de verilmiştir." Hem yaprak eni ve yaprak alanı hem de yaprak boyu ve yaprak alanı arasında yüksek düzeyde bir polinominal ilişki olduğu görülmektedir.

Çizelge 2. Farklı sulama düzeylerinin ortalama yaprak alanı üzerindeki etkisi ( $\mathrm{cm}^{2} /$ yaprak)

Table 2. The effect of different irrigation levels on average leaf area $\left(\mathrm{cm}^{2} /\right.$ leaf)

\begin{tabular}{lllllll}
\hline Uygulama & $\mathrm{N}$ & Ortalama & Standart Sapma & Standart Hata & & \\
\hline $\mathrm{I}_{50} \mathrm{Ca}_{0}$ & 114 & 100.25 & 66.55 & 6.23 & 276.31 & 18.75 \\
$\mathrm{I}_{50} \mathrm{Ca}_{5}$ & 120 & 117.66 & 75.64 & 6.90 & 313.00 & 20.71 \\
$\mathrm{I}_{50} \mathrm{Ca}_{10}$ & 221 & 120.35 & 72.64 & 4.88 & 355.23 & 20.23 \\
$\mathrm{I}_{50} \mathrm{Ca}_{20}$ & 122 & 134.66 & 101.05 & 9.14 & 408.19 & 17.83 \\
$\mathrm{I}_{50} \mathrm{Ca}_{30}$ & 120 & 144.08 & 107.51 & 9.81 & 406.86 & 17.08 \\
$\mathrm{I}_{75} \mathrm{Ca}_{0}$ & 152 & 89.78 & 62.87 & 5.10 & 320.15 & 13.21 \\
$\mathrm{I}_{75} \mathrm{Ca}_{5}$ & 36 & 159.15 & 96.02 & 16.00 & 347.86 & 20.45 \\
$\mathrm{I}_{75} \mathrm{Ca}_{10}$ & 129 & 123.07 & 101.81 & 8.96 & 380.61 & 16.33 \\
$\mathrm{I}_{75} \mathrm{Ca}_{20}$ & 206 & 96.74305 & 69.0345 & 4.809861 & 329.4259 & 15.2405 \\
$\mathrm{I}_{75} \mathrm{Ca}_{30}$ & 145 & 135.9605 & 73.94471 & 6.140774 & 344.0542 & 21.8495 \\
$\mathrm{I}_{100} \mathrm{Ca}_{0}$ & 90 & 102.4206 & 60.37549 & 6.364135 & 239.591 & 20.1284 \\
$\mathrm{I}_{100} \mathrm{Ca}_{5}$ & 142 & 123.4871 & 87.94234 & 7.379957 & 352.4924 & 15.7242 \\
$\mathrm{I}_{100} \mathrm{Ca}_{10}$ & 151 & 118.9078 & 90.95052 & 7.401448 & 380.4803 & 17.7333 \\
$\mathrm{I}_{100} \mathrm{Ca}_{20}$ & 180 & 125.2277 & 86.37934 & 6.438336 & 422.0348 & 21.107 \\
\hline $\mathrm{I}_{100} \mathrm{Ca}_{30}$ & 178 & 165.4221 & 111.486 & 8.356231 & 494.1347 & 18.6792 \\
\hline
\end{tabular}




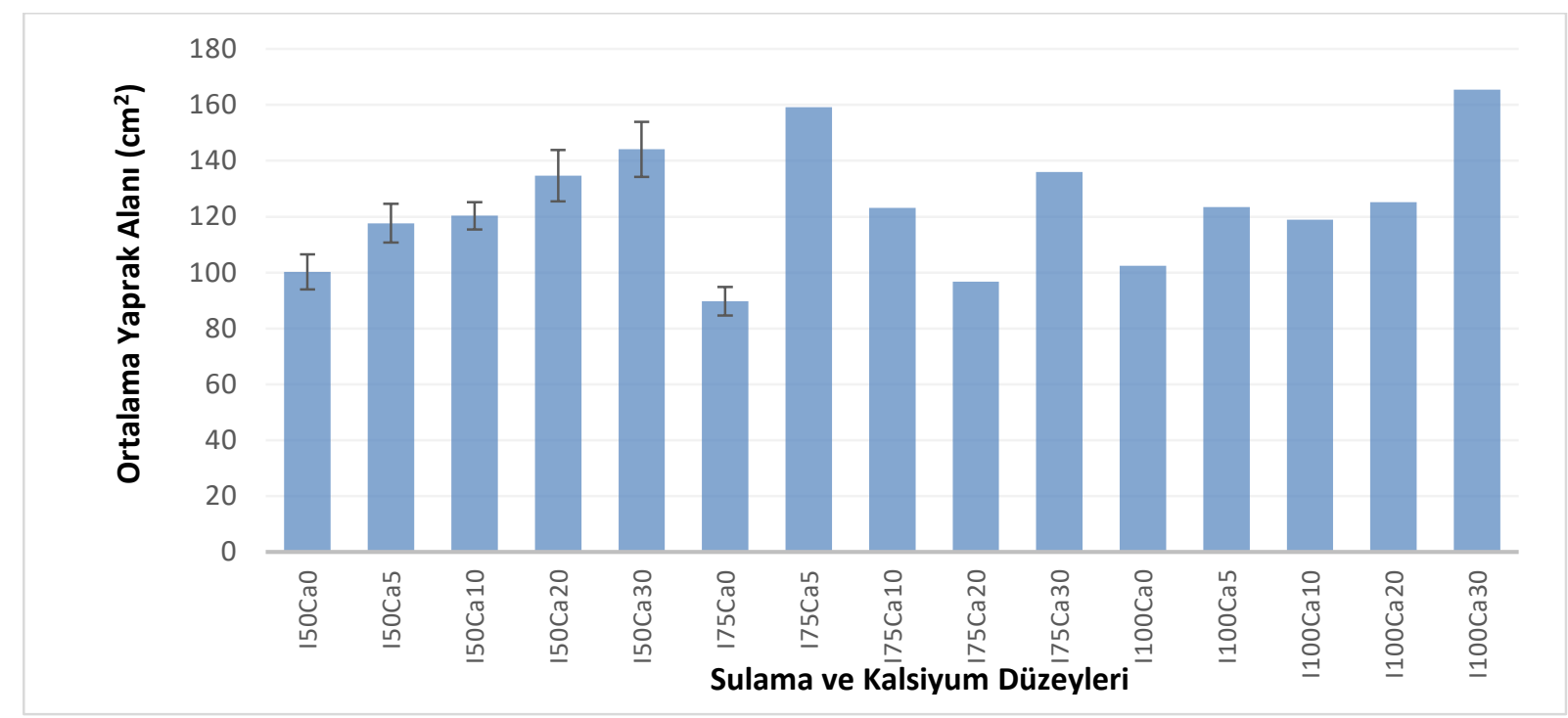

Şekil 2. Farklı sulama ve kalsiyum düzeylerinin ortalama yaprak alanı üzerindeki etkisi

Figure 2. The effect of different irrigation and calcium levels on average leaf area

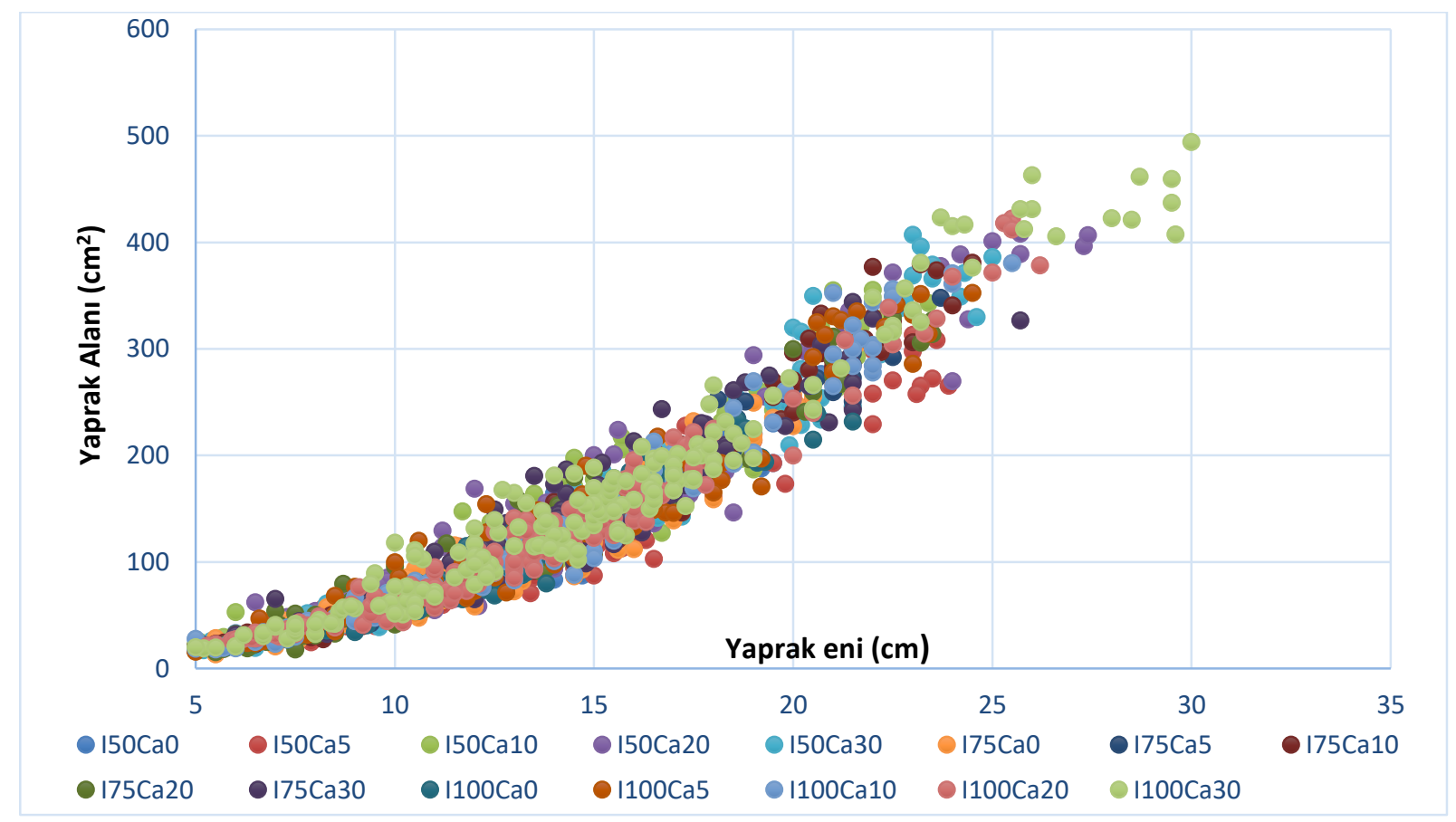

Şekil 3. Farklı kalsiyum dozları ve sulama düzeyinde yaprak eni ve yaprak alanı arasındaki ilişkiler Figure 3. Relationships between leaf width and leaf area at different calcium doses and irrigation levels 


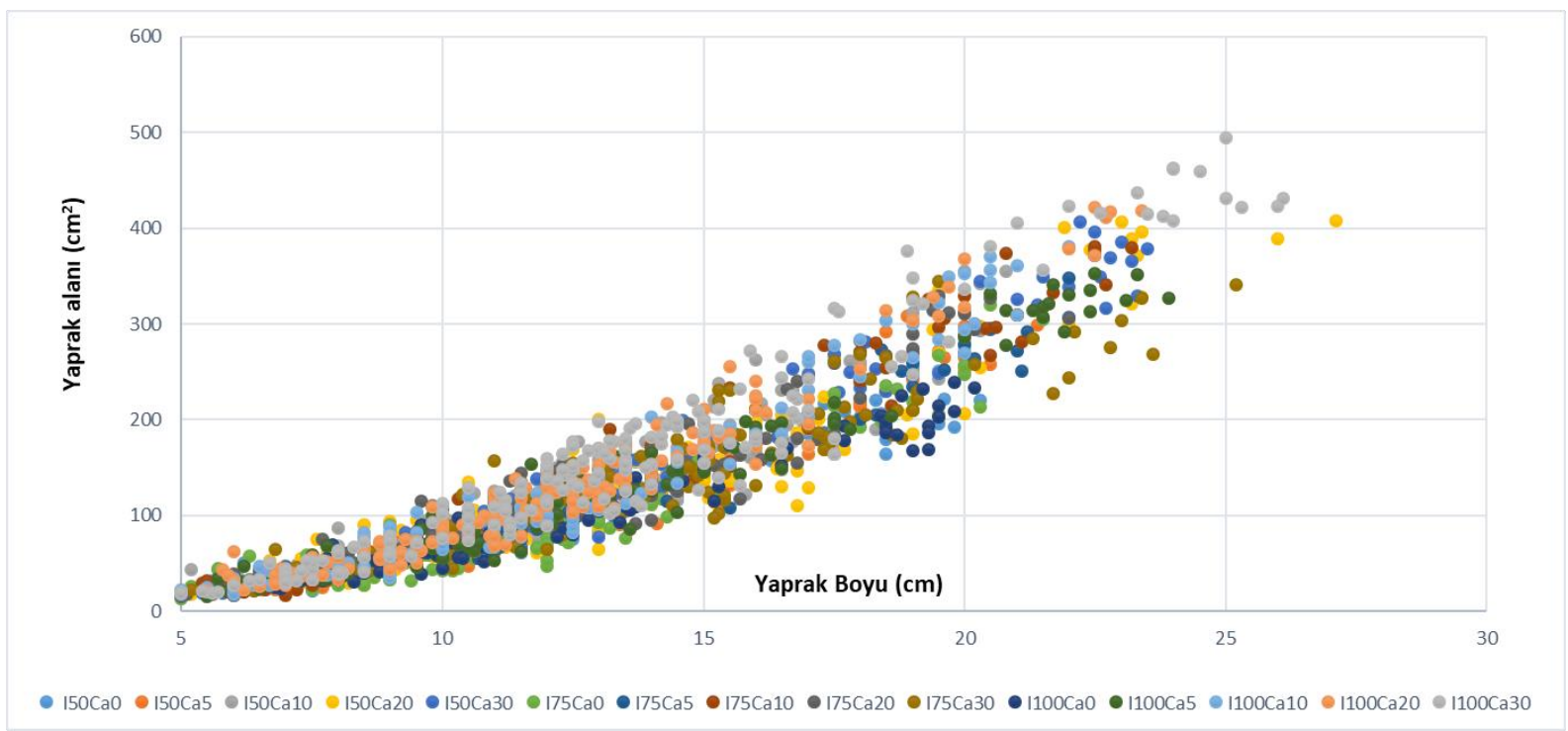

Şekil 4. Farklı kalsiyum dozları ve sulama düzeyinde yaprak boyu ve yaprak alanı arasındaki ilişkiler Figure 4. Relationships between leaf length and leaf area at different calcium doses and irrigation level

Yapılan incelemelerde farklı sulama düzeylerinin yaprak eni veya yaprak boyu ile yaprak alanı arasındaki ilişkiyi önemli düzeylerde etkilemediği görülmüştür (Şekil 5 ve Şekil 6). Bu sebeple modelleme aşamasında tüm sulama düzeylerinde ölçülen veriler veri sayısını artırmak ve bu yolla elde edilecek denklemlerin temsil yeteneğini artırmak için birleştirilmiştir (Şekil 7).
Şekil 5, 6 ve 7 incelendiğinde verilerde önemli bir dağılma veya farklılaşma olmadığı görülmektedir. Birleştirilmiş verilerden elde edilen grafikten de anlaşıldığı üzere (Şekil 8), yaprak eni ile yaprak alanı ilişkisi yaprak boyu ve yaprak alanı ilişkisine göre daha homojen veri dağılımı $\left(R^{2}=0.95\right)$ göstermiştir.



Şekil 5. Birleştirilmiş yaprak verilerinde yaprak eni ve yaprak alanı arasındaki ilişki

Figure 5. Relationship between leaf width and leaf area in combined leaf data 




Şekil 6. Birleştirilmiş yaprak verilerinde yaprak boyu ve alanı arasındaki ilişki

Figure 6. Relationship between leaf length and area in combined leaf data

Yaprak eni ile yaprak alanı ve yaprak boyu ile yaprak alanı arasında doğrusal olmayan bir ilişki olduğu görüldüğünden (Şekil 6), çalışmanın amacı doğrultusunda, veriyi doğrusal hale getirmek için yaprak eninin ve yaprak boyunun karesi alınarak veri dönüşümü yapılmıştır. Dönüşüm yapılan veriler arasındaki ilişkiler belirlenmek üzere Şekil 7'de grafiklenmiştir.



Şekil 7. Yaprak eninin karesi ile yaprak alanı arasındaki ilişki (Birleştirilmiş veri) Figure 7. Relationship between leaf width square and leaf area (Combined data) 


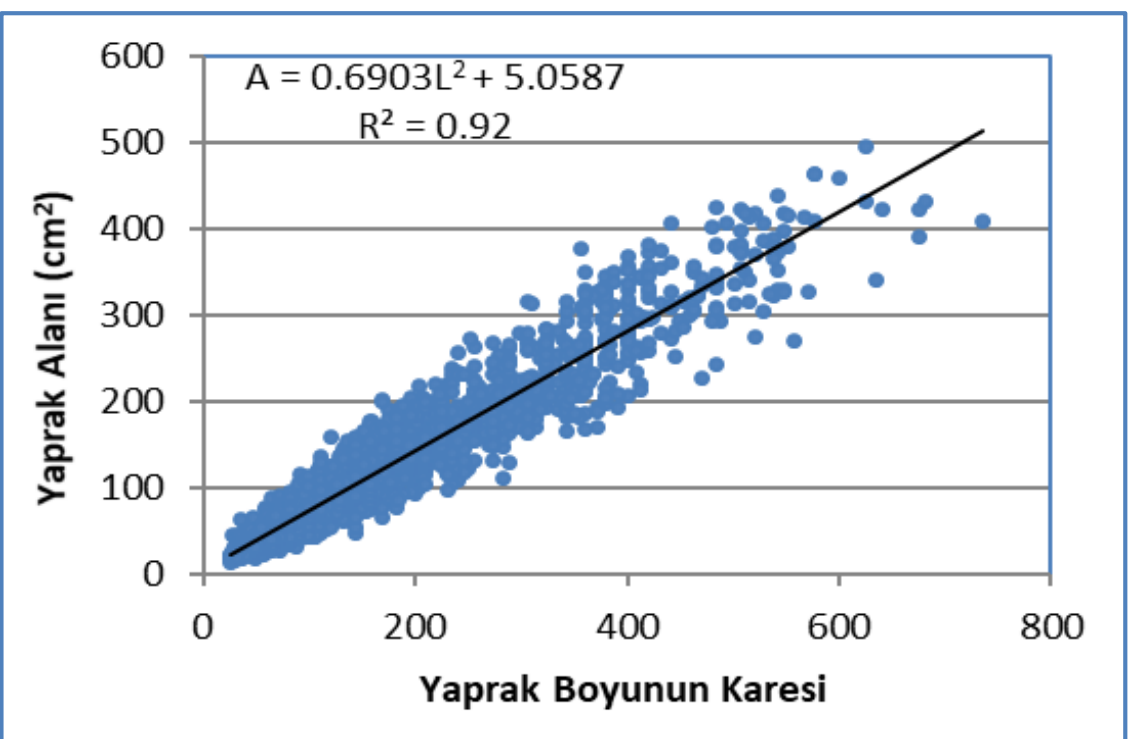

Şekil 8. Yaprak boyunun karesi ile yaprak alanı arasındaki ilişki (Birleştirilmiş veri)

Figure 8. The relationship between the square of the leaf length and leaf area (Combined data)

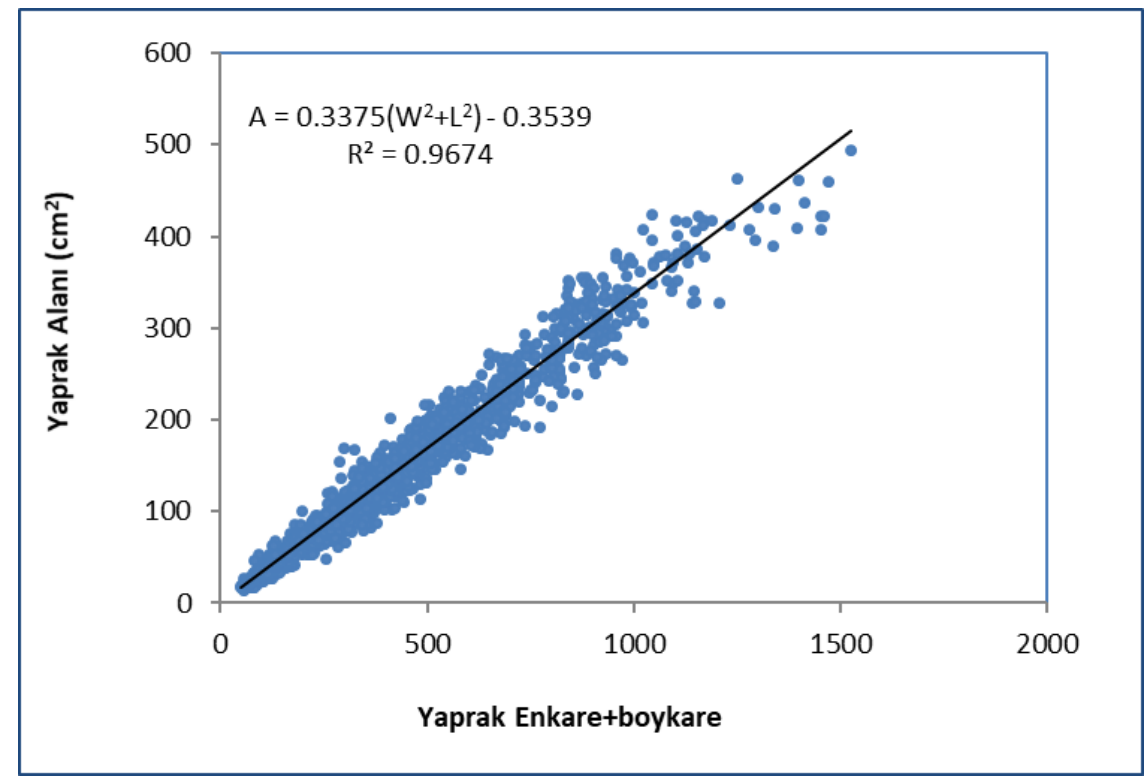

Şekil 9. Yaprak boyunun karesi + eninin karesi ile yaprak alanı arasındaki ilişki (Birleştirilmiş veri)

Figure 9. Relationship between leaf length square + width square and leaf area (Combined data)

Veri analizinin modelleme aşamasında beş model geliştirilmiştir. Bunlar:

1) Yaprak eninden yaprak alan tahmini (Model 1)

2) Yaprak boyundan yaprak alan tahmini (Model 2)

3) Yaprak eninin karesinden yaprak alan tahmini (Model

3)

4) Yaprak boyunun karesinden yaprak alan tahmini (Model 4)
5) Yaprak eninin karesinden ve yaprak boyunun karesi toplamından alan tahmini (Model 5)

Model eşitlikleri ve modellere ilişkin RMSEP ve $R^{2}$ değerleri Çizelge 4 'de verilmiştir. Ölçülen yaprak alanı ile tahmin edilen yaprak alanı arasındaki ilişkiyi gösteren grafikler ise Şekil 9, 10 ve 11'de verilmiştir. 
Çizelge 4. Yaprak alanı tahmini model eşitlikleri ve modellere ilişkin RMSEP ve $\mathrm{R}^{2}$ değerleri Table 4. Leaf area estimation model equations and RMSEP and $R^{2}$ values for the models

\begin{tabular}{llll}
\hline Model No & Model Eşitliği & RMSEP & $\mathbf{R}^{\mathbf{2}}$ \\
\hline 1 & $0.5364 \mathrm{~W}^{2}+2.3563 \mathrm{~W}-12.378$ & 19.98 & 0.95 \\
2 & $0.5963 \mathrm{~L}^{2}+2.6531 \mathrm{~L}-11.558$ & 25.41 & 0.92 \\
3 & $0.6144 \mathrm{~W}^{2}+3.3879$ & 20.10 & 0.95 \\
4 & $0.6903 \mathrm{~L}^{2}+5.0587$ & 25.50 & 0.92 \\
5 & $0.03375\left(\mathrm{~W}^{2}+\mathrm{L}^{2}\right)-0.3539$ & 15.76 & 0.97 \\
\hline
\end{tabular}

Model 1 çalışmasında doğrudan ölçülen ve yaprak eninden tahmin edilen alanlar arasında $R^{2}=0.95$ güvenilirlik düzeyinde bir ilişki gözlenmektedir. Ancak anılan modelin RMSEP değerinin (19.98 yüksek olması modelin geçerliliğini zayıflatmaktadır.



Şekil 10. Model 1 için ölçülen yaprak alanı ile tahmin edilen yaprak alanı arasındaki ilişki Figure 10. Relationship between measured leaf area and predicted leaf area for Model 1

Model 2 çalışmasında ise doğrudan ölçülen ve yaprak boyundan tahmin edilen alanlar arasında Model 1'e göre daha düşük bir ilişki $\left(R^{2}=0.92\right)$ olduğu belirlenmiştir.
Zaten bu modelin RMSEP değeri (3.66) en yüksek çıkmış ve bu modelin zayıflığını göstermektedir. 


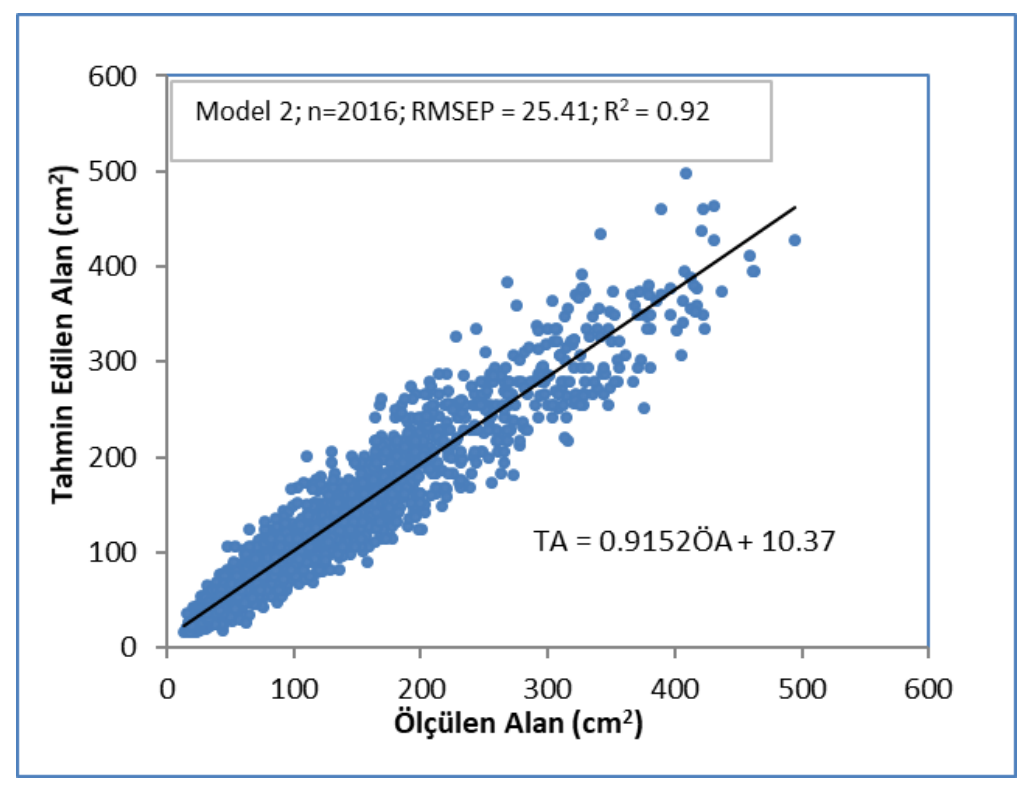

Şekil 11. Model 2 için ölçülen yaprak alanı ile tahmin edilen yaprak alanı arasındaki ilişki Figure 11. Relationship between measured leaf area and predicted leaf area for Model 2

Model 3 çalışmasında doğrudan ölçülen ve yaprak eninin karesinin kullanılarak tahmin edilen alanlar arasında $\mathrm{R}^{2}=0.95$ düzeyinde bir ilişki olduğu gözlenmiştir. Ancak bu modelin RMSEP değeri (20.10 sadece yaprak eni kullanılan modelin RMSEP değerinden daha yüksek bir değere sahiptir. Bu tespit 3. model yerine birinci modelin daha doğru tahmin sonuçları verdiğini göstermektedir.



Şekil 12. Model 3 için ölçülen yaprak alanı ile tahmin edilen yaprak alanı arasındaki ilişki

Figure 12. Relationship between measured leaf area and predicted leaf area for Model 3

Model 4 çalışmasında doğrudan ölçülen ve yaprak boyunun karesinin kullanılarak tahmin edilen alanlar arasında $R^{2}=0.92$ düzeyinde bir ilişki olduğu gözlenmiştir. Ancak bu modelin RMSEP değeri (25.50 tüm modeller içinde en yüksek değer olarak tespit edilmiştir. RMSEP değerinden çok yüksek olduğu için en başarısız model olmuştur. 


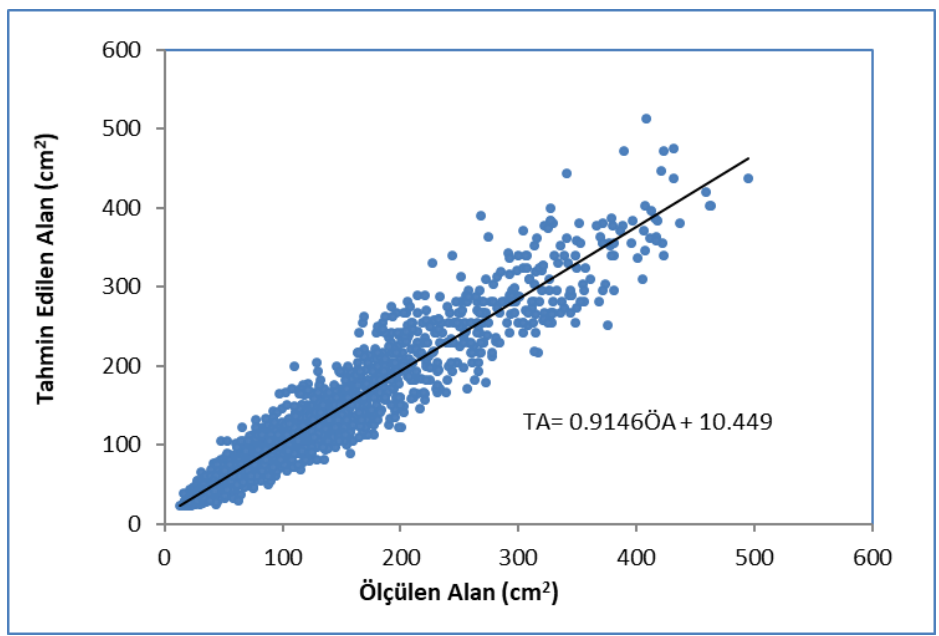

Şekil 13. Model 4 için ölçülen yaprak alanı ile tahmin edilen yaprak alanı arasındaki ilişki Figure 13. Relationship between measured leaf area and predicted leaf area for Model 4

Model 5 çalışmasında doğrudan ölçülen ve yaprak eni ve boyunun kareleri toplamının kullanılarak tahmin edilen alanlar arasında $\mathrm{R}^{2}=0.97$ düzeyinde bir ilişki olduğu gözlenmiştir. Bu model en düşük RMSEP değeri (15.76 ve en yüksek $R^{2}$ değerleri nedeniyle yapılan modellemeler içinde en kesin alan tahmini yapabilen ve en güvenilir model olarak kabul edilmiştir.



Şekil 14. Model 5 için ölçülen yaprak alanı ile tahmin edilen yaprak alanı arasındaki ilişki Figure 14. Relationship between measured leaf area and predicted leaf area for Model 5

Yapılan çalışma, yaprak alanlarının kolaylıkla, yaprak boyutlarının bir kompas yardımıyla ölçülüp doğrudan belirlenebileceğini göstermiştir. En uygun yaprak alanı belirlemesi: Yaprak Alanı $\left(\mathrm{cm}^{2}\right)=0.3375 *\left(\mathrm{~W}^{2}+\mathrm{L}^{2}\right)-$ 0.3539 (RMSEP $=15.76$ and $R^{2}=0.97$ ) modeli ile gerçekleştirilebilmiştir. Kavun yaprak alan belirlemesi için çok pahalı ve hassas cihazlara gerek olmadan bu denklem kullanılarak rahatlıkla yaprak alanları belirlenebilir ve böylece aynı yaprak üzerinde sürdürülen çalışmalara yapraklara zarar vermeden devam edilebilecektir. Bunun yanı sıra yapılacak çalışmaların bütçeleri azalarak, zamandan tasarruf edilebilecektir.

\section{ÖZET}

Amaç: Bitkilerin yaprak alanının belirlenmesinde kullanılan basit, doğru ve bitkiye zarar vermeyen yöntemler, birçok deneysel karşılaştırmada önemli yer tutmaktadır. Bu çalışmada serada yetiştirilen kavun bitkisinin farklı kalsiyum düzeyleri $(0,5,10,20$ ve 30 $\mathrm{kg} / \mathrm{da}$ ) ve farklı sulama suyu miktarları $(150,175$, ve 1100$)$ altında yaprak alan modellerinin geliştirilmesi ve bu modelden faydalanılarak bitkilere zarar vermeden yaprak alanlarının belirlenmesi amaçlanmıştır.

Yöntem ve Bulgular: Bu amaçla her uygulamadan $30^{\prime}$ ar 
adet yaprak toplanmış (toplam 1350 adet) ve bu yaprakların en $(\mathrm{W})$ ve boy $(\mathrm{L})$ ölçümleri dijital kumpasla yapılırken, yaprak alanı (LA) ölçümleri dijital planimetre ile yapılmıştır. Yaprak eni, yaprak boyu ve yaprak alanı değerleri arasındaki ilişkiler MS-Excel 2010 (Microsoft Inc.) yazılımı ile grafiksel olarak incelenmiştir. Yaprak eni, yaprak boyu ve yaprak alanı değerleri arasındaki matematiksel tahmin modelleri ise; Unscrambler yazılımında (Versiyon 9.7, Camo Software, Norway) MLR (Multiple Linear Regression) yöntemine göre oluşturulmuştur. Tahmin modelinin doğrulanması için Tam Çapraz Geçerlilik (Full Cross Validation) yöntemi uygulanmıştır. Modellerin karşılaştırılması amacıyla her bir model için Unscrambler yazılımından elde edilen RMSEP (Root Mean Square Error of Prediction) ve $R^{2}$ değerleri kullanılmıştır. Kısıtlı su uygulamalarının ortalama yaprak alanını azalttığı belirlenmiş ve bu bağlamda en başarılı modelin; Yaprak Alanı $\left(\mathrm{cm}^{2}\right)=$ $0.3375 *\left(\mathrm{~W}^{2}+\mathrm{L}^{2}\right)-0.3539\left(\mathrm{RMSEP}=15.76\right.$ ve $\left.\mathrm{R}^{2}=0.97\right)$ olduğu belirlenmiştir.

Genel Yorum: Oluşturulan matematiksel model yardımıyla özellikle bitki gelişimi ile ilgili tüm tarımsal araştırmalarda çok pahalı cihazlarla ve/veya bitki sökümü yapılarak gerçekleştirilebilen bitki yaprak alanları ve Yaprak Alan İndeksi (LAI) değerleri basit doğrudan ölçümlerle belirlenebilecektir. Aynı zamanda yetiştirme sezonu boyunca aynı yaprak üzerinde ölçümlerin alınması da mümkün olabilecektir.

Çalışmanın Önemi ve Etkisi: Bu çalışma ile bilgisayara yükleyebildiğimiz basit bir yazılım sayesinde kavunda yaprak alan ölçümlerinin daha kısa sürede ve daha az hata ile sonuçlandırılması amaçlanmıştır. Elde edilen verilerle geliştirilen model yardımıyla kavun üzerinde yapılacak fizyolojik, morfolojik ve diğer çalışmalarda kullanılan toplam yaprak alanının hesaplanmasında özellikle araştırma yapan bilim insanlarına faydalı olacaktır. Bu çalışmadan yararlanılarak ve benzer yöntemlerle diğer bitkiler içinde model oluşturmak mümkün olacaktır.

Anahtar Kelimeler: Yaprak alanı, Büyüme modeli, Yaprak alan indeksi, Su stresi.

\section{TEŞEKKÜR}

Çalışmamıza maddi destek veren HMKÜ BAP (proje numarası $18 \mathrm{M}$ 049) koordinatörlüğüne teşekkür ederiz.

\section{ÇIKAR ÇATIŞMA BEYANI}

Yazar(lar) çalışma konusunda çıkar çatışmasının olmadığını beyan eder.

\section{ARAŞTIRMACILARIN KATKI ORANI BEYANI}

Yazarlar çalışmaya eşit oranda katkı sağlamış olduklarını beyan eder.

\section{KAYNAKLAR}

Anonim (2019) TUik, 2019. Türkiye İstatistik Kurumu, Bitkisel Üretim İstatistikleri, 2019. tuik.gov.tr

Bozkurt S, Sayılıkan Mansuroğlu G (2019) Biber bitkisinde doğrusal ölçümlerle yaprak alan modelinin oluşturulması. MKÜ Tar. Bil. Derg. 24(2): 77-86.

Çamaş N, Ayan AK, Esendal E (2005) Leaf area prediction model for safflower (Carthamus tinctorius L.) Pakistan Journal of Biological Sciences 8(11): 15411543.

Capell T,Bassie L, Christou P (2004) Modulation of hepolyamine biosynthetic pathway in transgenic rice confers tolerance to drought stress. Pnas. 101(26): 9909-9914.

Centritto M, Loreto F, Massacci A,Pietrini F, Villani MC, Zacchine M (2000) Improved Growth and Water Use Efficiency of Cherry Saplings under Reduced Light Intensity. Ecol. Res. 15: 385-392.

Çevik B, Kanber R, Biçici M, Pakyürek Y, Köksal H (1992) Sera koşullarında yetiştirilen hıyarda değişik toprak örtü materyallerinin verim, kalite ve su tüketimine etkileri. Türkiye I. Ulusal Bahçe Bitkileri Kongresi, Cilt II, Ege Üni. Ziraat Fakültesi, İzmir.

Esbensen KH (2009) Multivariate Data Analysis-In Practice. 5th Edition. Camo. Norway.

Gomez KA,Gomez AA (1984) Statistical Procedures for Agricultural Research. John Wiley and Sons, New York.

Gülümser A, Bozoğlu H, Peşken E (1998) Yemeklik Tane Baklagiller (Uygulama Kitabı). OMÜ. Ziraat Fak. Ders Kitabı No.27. Samsun.

Guo DP, Sun YZ (2001) Estimation of leaf area of stem lettuce (Lactuca sativa var. angustana) from linear measurements. Indian J. Agric. Sci. 71(7): 483-486.

Jaleel CA, Manivannan P, Sankar B, Kishorekumar A, Gopi R, Somasundaram R, Panneerselvam R (2007) Water deficit stress mitigation by calcium chloride in Catharanthus roseus: Effects on oxidativestress, proline metabolism andindole alkaloid accumulation. Biointerfaces 60: 110-116.

Kandiannan K, Kailasam C, Chandaragiri KK, Sankaran N (2002) Allometric model for leaf area estimation in black pepper (Piper nigrum L.). J. Agron. Crop Sci. 188: 138-140. 
Kanemasu ET, Asrar G, Fuchs M (1985) Application of remotely sensed data in wheat growth modelling. In: Wheat Growth and Modelling, Eds.: W. Day and R.K. Atkin. Nato Asi Series, Series A: Life Sciences, 86, 357369.

Kaygısız H (2000) Sebzecilik Genel Teknikler Özel Uygulamalar (Domates, Biber, Patlıcan, Hıyar). Genişletilmiş íkinci Baskı, Hasad Yayıncılık Ltd. Şti., İstanbul.

Koç M, Barutçular C (2000) Buğdayda çiçeklenme dönemindeki yaprak alanı indeksi ile verim arasındaki ilişkinin Çukurova koşullarındaki durumu. Turk Journal Agric For. 24: 585-593.

Kocaçalışkan i (2003) Bitki Fizyolojisi. DPÜ Fen-Edebiyat Fakültesi Yayını, $420 \mathrm{~s}$.

Longnecker $N$ (1994) Nutrient deficiencies and vegetative growth. In Mechanisms of Plant Growth and Improved Productivity; Basra, A.S., Ed.; Marcel Dekker: New York, 137-172.

Manivel L, Weaver JC (1974) Biometric correlations between leaf area and length measurements of Grenache grape leaves . Hortscience 9(1): 27-28.

Marschner H (1995) Mineral nutrition of higherplants, Acad. Pres., 2nd.ed., London.

Preece JE, Read PE (1993) The Biology of Hort. in Introductory Textbook, p:263-269.
Reddy AR, Chaitanya KV, Jutur PP, Sumithra K (2004) Differential antioxidative responses to water stres among five mulberry (Morus alba L.) cultivars. Environ. Exp. Bot. 52: 33-42.

Robbins NS, Pharr DM (1987) Leaf area prediction models for Cucumber from linear measurements. Hortscience 22(6): 1264-1266.

Sepaskhah AR (1977) Estimation of individual and total leaf areas of safflowers. Agron. J. 69(5): 783-785.

Splittstoesser WE (1990) Vegetable Growing Handbook, Organic and Traditional Methods, Plant Physiology in Horticulture University of Illinois, Urbana, Illinois, p:112-115.

Stewart DW, Dwyer LM (1993) Mathematical characterization of maize canopies. Agr. Forest Meteorol. 66: 247-265.

Strik BC, Proctor JTA (1985) Estimating the area of trifoliolate and unequally imparipinnate leaves of strawberry. Hortscience 20(6): 1072-1074.

Tuna AL, Özer Ö (2005) Farklı kalsiyum bileşiklerinin karpuz (Citrullus lanatus) bitkisinde verim, beslenme ve bazı kalite özellikleri üzerine etkisi. Ege Üniv. Ziraat Fak. Derg. 42(1): 203-212.

Yarşı G, Sarı N (2006) Aşılı fide kullanımının sera kavun yetiştiriciliğinde beslenme durumuna etkisi. Alatarım Dergisi 5(2): 1-8. 